CASE SERIES AND REPORTS

\title{
Idiopathic SIADH in young patients: don't forget the nose
}

\author{
SIADH idiopatica in pazienti di giovane età: non dimenticare il naso \\ C. PARRILLA' ${ }^{1}$, D. LUCIDI' ${ }^{1}$, G. PETRONE³ ${ }^{3}$, G. BASTANZA' ${ }^{1}$, C. COLOSIMO² \\ ${ }^{1}$ Institute of Otolaryngology Catholic university of Sacred Heart, Rome, Italy; ${ }^{2}$ Institute of Radiology, Catholic \\ University of Sacred Heart, Rome, Italy; ${ }^{3}$ Institute of Pathological Anatomy and Cytopathology, Catholic University of \\ Sacred Heart, Rome, Italy
}

\section{SUMMARY}

Olfactory neuroblastoma (ONB) is an uncommon neuroendocrine sinonasal cancer associated by many authors to ectopic production of several biologically active substances. We report a case of a 31-year-old male patient who presented with idiopathic syndrome of inappropriate secretion of antidiuretic hormone (SIADH). During diagnostic work-up, a CT scan of the head was performed and an ethmoidal ONB was detected. Endoscopical surgery followed by radiotherapy was carried out. Immediately after surgery natraemia levels normalised. Five years later the patient is disease-free. To our knowledge, 17 cases of SIADH associated to ONB have been published. In nine reports, idiopathic SIADH promptly led to the diagnosis of the sinonasal mass as in our clinical case, however, in many reports, correct diagnosis was accomplished months to years later. In young patients with idiopathic inappropriate antidiuretic hormone secretion, a neuroendocrine malignancy of the sinonasal area must be excluded.

KEY WORDS: Olfactory neuroblastoma $\bullet$ SIADH $\bullet$ Paraneoplastic syndrome $\bullet$ Arginine vasopressin $\bullet$ Sinonasal

\section{RIASSUNTO}

Il neuroblastoma olfattivo $(O N B)$ è un raro tumore neuroendocrino dei seni paranasali associato, secondo molti autori, alla produzione di molteplici sostanze biologicamente attive. In questo lavoro descriviamo il caso di un paziente di sesso maschile di 31 anni giunto alla nostra osservazione presentando la sindrome idiopatica da inappropriata secrezione di ormone antidiuretico (SIADH). Durante il work-up diagnostico il paziente è stato sottoposto a TAC del massiccio facciale, che documentava la presenza di un estesioneuroblastoma etmoidale. è stato eseguito un trattamento di chirurgia endoscopica e successiva radioterapia. Subito dopo l'intervento chirurgico i livelli di natremia si sono normalizzati. Cinque anni più tardi il paziente risulta essere libero da malattia. Attualmente in letteratura sono stati pubblicati 17 casi di SIADH associata a ONB. In nove lavori la SIADH idiopatica ha tempestivamente portato alla diagnosi di masse sinusali come nel nostro caso, tuttavia, in molti casi, si è giunti alla diagnosi corretta mesi o anni dopo. Nei giovani pazienti con sindrome idiopatica da inappropriata secrezione di ormone antidiuretico è necessario escludere un tumore maligno neuroendocrino dei seni paranasali.

PAROLE CHIAVE: Neuroblastoma olfattivo $\bullet$ SIADH $\bullet$ Sindrome paraneoplastica $\bullet$ Arginina vasopressina $\bullet$ Seni paranasali

Acta Otorhinolaryngol Ital 2017;37:76-79

\section{Introduction}

Syndrome of inappropriate secretion of antidiuretic hormone (SIADH) or Schwartz-Bartter syndrome is characterised by excessive levels or activity of arginine vasopressine (AVP) with hyponatraemia and hyposmolality. High urinary sodium concentration without salt and water intake alterations is present. Usual causes of SIADH are drugs, intracranial pathology, trauma and predominantly paraneoplastic syndromes. Most commonly paraneoplastic syndrome is related to small-cell carcinoma of the lung. Many studies have also been conducted about incidence of SIADH in head and neck cancer ${ }^{12}$ reporting $3 \%$ of patients affected by apparently idiopathic hyponatraemia. Most tumours are squamous cell carcinomas, but a small number of neuroendocrine sinonasal carcinomas have been reported. The prevailing phenotype is esthesioneuroblastoma (ENB) or olfactory neuroblastoma, first described by Berger in $1924^{3}$, which is known to be capable of producing biologically active substances such as somatostatin, calcitonin and vasoactive polypeptides. Olfactory neuroblastoma has been reported to be responsible for development of SIADH, especially in young patients. To our knowledge, 17 reports ${ }^{4-18}$ of SIADH induced by olfactory neuroblastoma have been published.

\section{Case report}

A 31-year-old man was admitted to a North American hospital with complaints of nausea, dizziness and weak- 

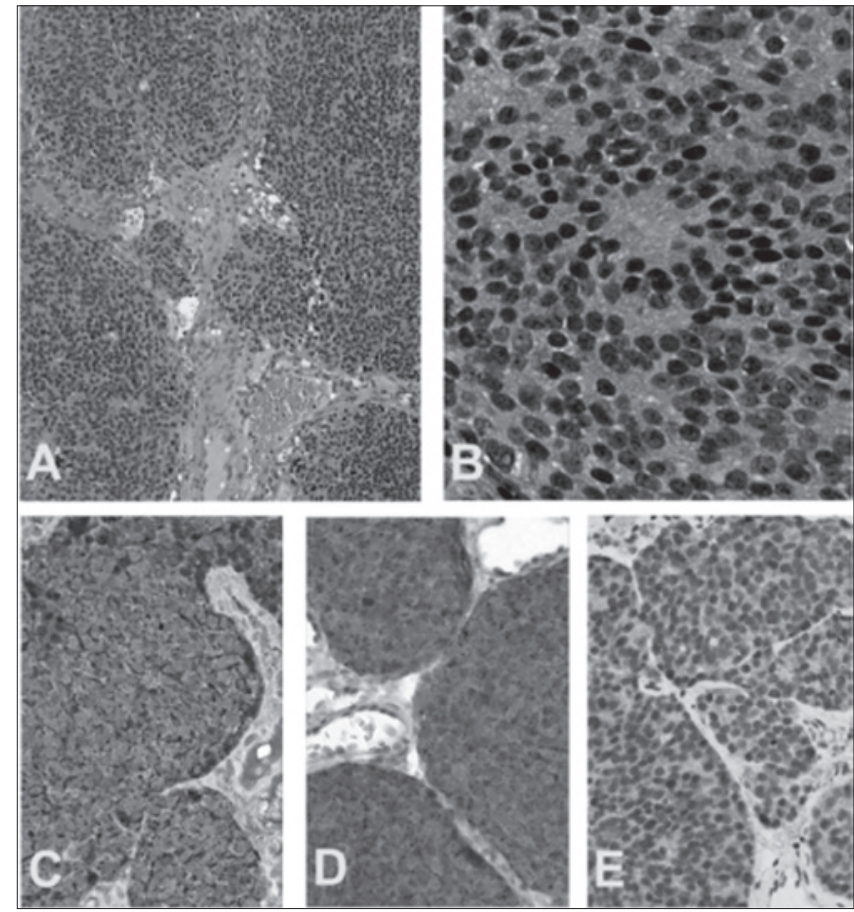

Fig. 1A. The tumour shows a nodular grow pattern composed by monomorphic round to oval neoplastic cells. (Haematoxylin and eosin, original magnification $\times 100$ ). B. Tumour cells with finely granular nuclei and scant cytoplasm with neurofibrillary matrix forming Homer-Wright rosettes. (Haematoxylin and eosin, original magnification $\times 400$ ). C-D-E. Tumour cells exhibiting diffuse cytoplasmatic immunoreactivity for chromogranin A (C), synaptophysin (D) and NSE (E). (Haematoxylin counterstaining, original magnification $\times 200$ ).

ness for about a week. The patient was seen in an Urgent Care Centre and at physical examination temperature, heart rate, blood pressure and other vital criteria were normal: no cervical lymphadenopathy, no oedema was noted. The laboratory data reported a hypotonic hyponatraemia (serum sodium $111 \mathrm{mmol} / \mathrm{L}$, serum osmolality $237 \mathrm{mmol} /$ $\mathrm{kg}$ ) in a euvolemic, non-oedematous patient with normal levels of potassium, chloride, bicarbonate and creatinine. Urinary sodium was $58 \mathrm{mmol} / \mathrm{L}$, urinary osmolality was $266 \mathrm{mmol} / \mathrm{kg}$. The patient's hyponatraemia was interpreted as a chronic disease given the fact that even with a sodium of $111 \mathrm{mmol} / \mathrm{L}$ on admission he had no change in mental status. He was treated with fluid restriction and furosemide for 2 days but his sodium increased to only 116 . As patient continued to remain hyponatraemic despite resolution of nausea and pain, a CT scan of head, neck, chest and abdomen was performed, demonstrating a homogeneous mass lesion that expanded the right ethmoid. No evidence of lung masses or adenopathy were found. ENT consult was obtained and differential diagnosis was reported as a malignant lesion versus aggressive fungal infection. The patient was started on demeclocycline to inhibit ADH action with an increase in sodium to 129 on the day of discharge. A few days later an endoscopic biopsy of the right sinonasal mass under local anaesthesia was performed. At microscopic examination, the tumour was highly cellular and composed of

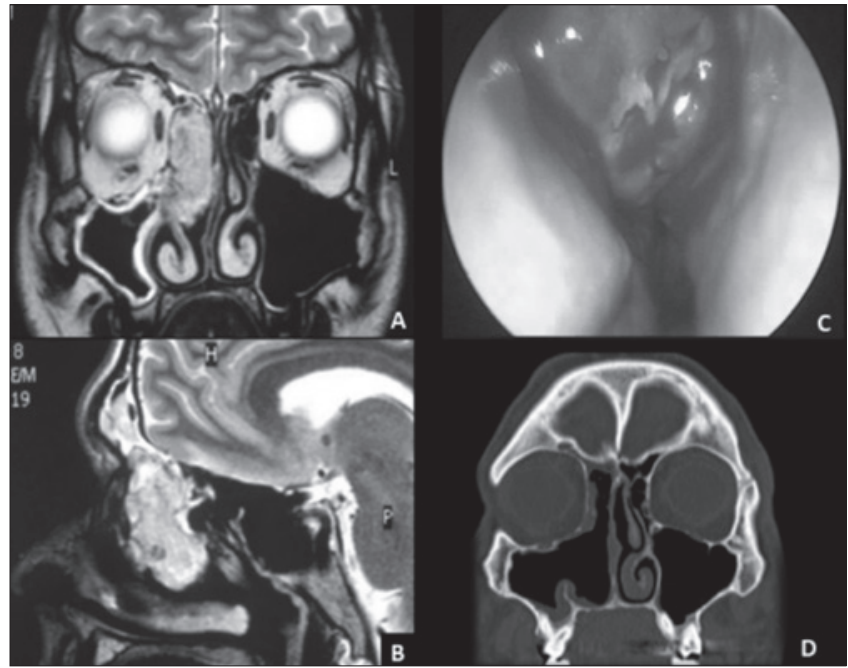

Fig. 2A-B. Coronal and sagittal T2-weighted images. Pre-operative MRI shows a large, well-defined mass expanding the right ethmoid. The mass lesion exhibits intermediate signal on T2-weighted images, due to its high cellularity; there is no evidence of infiltration of the orbital fat and of the fovea ethmoidalis. Inflammatory/obstructive changes are seen in both right frontal and maxillary sinuses due to mass effect on the ostio-meatal unit. Right lamina papyracea was compressed by the mass, but not interrupted; the orbit, anterior cranial fossa and brain were disease-free. C. Endoscopic view of the right nasal fossa: a fairly well circumscribed, multi-lobulated smooth rounded mass, involving the right ethmoid sinus and the region of middle turbinate is showed. Bony destruction was not recognisable, but the mass effect was prominent. D. Post-operative coronal CT image demonstrates the ethmoido-maxillectomy, without evidence of residual/recurrent disease.

round to oval neoplastic cells with slight nuclear pleomorphism and scant cytoplasm, organised in solid nests with sparse Homer-Wright rosettes. Scattered mitotic figures (up to $8 \times 10$ high power fields (HPF)) but no necrosis were found (Fig. 1). The proliferative index was 20\% (MIB1/ Ki-67). The neoplastic cells were stained positively with synaptophysin, chromogranin, NSE and CD56-NCAM. No immunostaining was observed for AE1/AE3, Cam 5.2 and $\mathrm{Bcl}-2$. These findings, together with the morphology, were consistent with the diagnosis of olfactory neuroblastoma.

The patient at this point made return to his home country and was admitted to our hospital for therapeutic planning. MR scan of the head and neck was performed (Fig. 2 A-B), results were consistent with the CT data, additional information were precise dimensions $(38 \times 16 \mathrm{~mm})$, slight nasal septum and nasolacrimal duct deformation. Endoscopic nasal evaluation was performed (Fig. 2C). According to Kadish grading ${ }^{19}$, the lesion was classified as stage B. After tumour board discussion, an endoscopic resection of the lesion without lamina cribra resection and duroplasty was performed (Fig. 2D). Serum natraemia levels normalised the day after surgery. Postoperative radiation therapy was administered. The patient underwent regular endoscopic and radiological follow-up and 5 years later is disease-free. 
Table I. Reported cases of Siadh secondary to olfactory neuroblastoma.

\begin{tabular}{|c|c|c|c|}
\hline Author & Age/Sex & Presentation & Tissue demonstration of AVP secretion \\
\hline Bouche 1967 & $34 / \mathrm{M}$ & Concomitant & No \\
\hline Singh 1980 & $17 / F$ & Concomitant & Yes \\
\hline Pope 1980 & $56 / F$ & Concomitant & No \\
\hline Sringley 1983 & $33 / F$ & SIADH (4 years earlier) & No \\
\hline Wade 1984 & $59 / F$ & Concomitant & No \\
\hline Osterman 1986 & 28/M & SIADH (6 years earlier) & Yes \\
\hline Cullen 1986 & $26 / F$ & SIADH (10 years earlier) & Yes \\
\hline Myers 1994 & $79 / F$ & Concomitant & No \\
\hline Al Ahwal 1994 & $27 / M$ & Concomitant & No \\
\hline Bernard 2000 & $22 / \mathrm{M}$ & Concomitant & Yes \\
\hline Muller 2000 & $47 / M$ & SIADH (15 months earlier) & No \\
\hline Miura 2001 & $56 / \mathrm{M}$ & Concomitant & Yes \\
\hline Plasencia 2006 & $34 / F$ & SIADH unmasked ONB relapse after 16 years & No \\
\hline Renneboog 2008 & $28 / F$ & SIADH (8 years earlier) & No \\
\hline Gray patient 12012 & 29/M & SIADH (5 months earlier) & Yes \\
\hline Gray patient 22012 & $25 / F$ & SIADH (3 years earlier) & Yes \\
\hline Gray patient 32012 & $32 / F$ & SIADH (8months earlier) & Yes \\
\hline
\end{tabular}

\section{Discussion}

Over the past 45 years 17 cases of SIADH associated with olfactory neuroblastoma were reported ${ }^{4-18}$. In all cases, the secretion of the neurohypophysial hormone manifested itself prior to the diagnosis of ONB. In most cases, the time between first determination of hyponatraemia and detection of the sinonasal mass was short, thus allowing to consider the two aspect concomitants. Limited reports demonstrate preexisting SIADH, in a patient otherwise asymptomatic, which was accordingly considered idiopathic for months to years (Table I).

Only in a few of the above-mentioned studies was AVP secretion directly demonstrated on frozen section sections, most commonly the relationship between high blood levels of AVP and aberrant neuroendocrine tumour secretion was considered consequential as natraemia rapidly increased to standard levels after successful treatment of ONB. In the totality of the reports, in fact, natraemia levels normalised immediately after ONB treatment was accomplished, independently from the oncologic outcome of the patient.

An interesting aspect, already mentioned by Gray and colleagues ${ }^{18}$ is the relatively young age of the small group of patients affected by this peculiar clinical lesion: average age at diagnosis was 37 years. Olfactory neuroblastoma mainly arises in two decades, the second and the fifth, although it is most commonly reported around the fiftieth year ${ }^{20}$.

SIADH as a paraneoplastic syndrome most commonly is related to small cell carcinoma of the lung and it reveals itself usually as a mild clinical picture. The accidental detection of a slight natraemia alteration, in fact, often leads to pulmonary investigation and allows to connect the two clinical aspects. On the contrary, as previously noticed ${ }^{16}$, most of the diagnoses of idiopathic hyponatraemia which revealed the neuroendocrine nasal disease were accomplished for severe nervous or systemic diseases. Nonetheless, in our opinion, even in the presence of mild clinical case it is advisable to suspect early a sinonasal involvement after pulmonary lesions are excluded, especially in young patients.

In a previous report ${ }^{16}$, alterations in serum sodium metabolism preannounced an olfactory neuroblastoma relapse, 16 years after first diagnosis, with no history of SIADH at the time of the first diagnosis. Pathological hyponatraemia and late lymph nodal relapse ${ }^{8}$ were reported as well. This aspects lead to consider that natraemia is a valuable follow-up tool in patients affected by olfactory neuroblastoma, with or without history of SIADH. Serum sodium evaluation is also an inexpensive, practical exam that can be easily performed during follow-up.

\section{Conclusions}

In patients affected by idiopathic SIADH, after a pulmonary primitive lesion has been excluded, the study of the sinonasal area must be included in diagnostic work-up. In patients with history of ONB, it is advisable to continue follow-up lifelong to detect late recurrences as early as possible, which unfortunately are very common in neuroendocrine tumours. Along with clinical and radiological inspection, we found that periodic natraemia evaluation is useful as an inexpensive, smart and safe means to detect ectopic production of AVP. SIADH, in fact, can arise as an indirect sign for ONB recurrence even if not assessed at first diagnosis. 


\section{References}

1 Ferlito A, Rinaldo A, Devaney KO. Syndrome of inappropriate antidiuretic hormone secretion associated with head and neck cancers: review of the literature. Ann Otol Rhinol Laryngol 1997;106(10 Pt 1):878-83.

2 Talmi YP, Hoffman HT, McCabe BF. Syndrome of inappropriate secretion of arginine vasopressin in patients with cancer of the head and neck. Ann Otol Rhinol Laryngol 1992;101:964-969.

3 Berger L, Luc R. L'esthèsioneuroèphiteliome olfactif. Bull de l'Assoc Franc pour l'Etude Cancer 1924;13:410-20.

4 Bouche J, Guiot G, Tessier P, et al. A further case of tumor of the olfactory placode. Sem Hop 1967;43:587-91.

5 Singh W, Ramage C, Best P, et al. Nasal neuroblastoma secreting vasopressin. A case report. Cancer 1980;45:961-6.

6 Pope TL Jr, Morris JL, Cail WS, et al. Esthesioneuroblastoma presenting as an intracranial mass. South Med J 1980;73:643-5

7 Sringley JR, Dayal VS, Gregor RT, et al. Hyponatremia secondary to olfactory neuroblastoma. Arch Otolaryngol 1983;109:559-62.

8 Wade PM Jr, Smith RE, Johns ME. Response of esthesioneuroblastoma to chemotherapy. Report of five cases and review of the literature. Cancer 1984;53:1036-41.

9 Osterman J, Calhoun A, Dunham M, et al. Chronic syndrome of inappropriate antidiuretic hormone secretion and hypertension in a patient with olfactory neuroblastoma. Evidence of ectopic production of arginine vasopressin by the tumor. Arch Intern Med 1986;146:1731-5.

${ }_{10}$ Cullen MJ, Cusack DA, O'Briain DS, et al. Neurosecretion of arginine vasopressin by an olfactory neuroblastoma causing reversible syndrome of antidiuresis. Am J Med 1986;81:911-6.
11 Myers SL, Hardy DA, Wiebe CB, et al. Olfactory neuroblastoma invading the oral cavity in a patient with inappropriate antidiuretic hormone secretion. Oral Surg Oral Med Oral Pathol 1994;77:645-50.

12 al Ahwal M, Jha N, Nabholtz JM, Hugh J, et al. Olfactory neuroblastoma: report of a case associated with inappropriate antidiuretic hormone secretion. J Otolaryngol 1994;23:437-9.

13 Bernard P, Vitrey D, Boursier C, et al. Olfactory esthesioneuroma manifesting as Schwartz-Bartter syndrome. Rev Med Interne 2000;21:278-81.

14 Müller MB, Landgraf R, Keck ME. Vasopressin, major depression, and hypothalamic-pituitary-adrenocortical desensitization. Biol Psychiatry 2000;48:330-3.

15 Miura K, Mineta H, Yokota N, et al. Olfactory neuroblastoma with epithelial and endocrine differentiation transformed into ganglioneuroma after chemoradiotherapy. Pathol Int 2001;51:942-7.

16 Plasencia YL, Cortés MB, Arencibia DM, et al. Esthesioneuroblastoma recurrence presenting as a syndrome of inappropriate antidiuretic hormone secretion. Head Neck 2006;28:1142-6.

17 Renneboog B, Decaux G. Idiopathic hyponatremia in a young patient: look at the sinus. Am J Med 2008;121:e5-6.

18 Gray ST, Holbrook EH, Najm MH, et al. Syndrome of inappropriate antidiuretic hormone secretion in patients with olfactory neuroblastoma. Otolaryngol Head Neck Surg 2012;147:147-51.

19 Kadish S, Goodman M, Wang CC. Olfactory neuroblastoma: a clinical analysis of 17 cases. Cancer 1976;37:1571-6.

20 Ow TJ, Bell D, Kupferman ME, et al. Esthesioneuroblastoma. Neurosurg Clin N Am 2013;24:51-65.

Address for correspondence: Lucidi Daniela, Catholic University of Sacred Heart, Institute of Otolaryngology, largo Francesco Vito 1, 00168 Rome, Italy. Tel. +39 06 30154439. Fax +39 063051194. E-mail: dani.lucidi@gmail.com 